\title{
Cantrell's pentalogy: long-term survival and repair of a large abdominal wall defect
}

\begin{abstract}
Cantrell's pentalogy is a congenital defect, described more than 50 years ago by Cantrell, Haller and Ravitch. Long term survival of patients with Cantrell's pentalogy is extremely rare. We report a case of pentalogy of Cantrell class 1 , that showed sternal cleft, left anterolateral diaphragmatic hernia, thoraco-abdominal ectopia cordis, diaphragmatic pericardial defect, patent ductus arteriosus and a large omphalocele. Initial surgery was done in his first day of life, obtaining partial correction of the defect and allowing survival with good quality of life. At the age of 18 years, he showed an abdominal wall defect measuring $22 \times 24 \mathrm{~cm}$, with near-total eventration of the liver and small bowel. Surgical correction consisted on visceral partial reduction and abdominal wall closing with a microporous polytetrafluoroethylene mesh and dermal flaps. Judicious combination of reconstructive techniques obtained long term survival free of symptoms and excellent aesthetic results.
\end{abstract}

Keywords: pentalogy of cantrell, cardiac defects, ventral hernia repair, polytetrafluoroethylene mesh, appedectomy, cholecystectomy, epiplonectomy
Volume 4 Issue 3 - 2018

\author{
Vivas-Colmenares GV, , ${ }^{1,2}$ Gómez Cía T, ${ }^{3}$ \\ Jiménez Crespo V,' Maraví A,' De Agustín JC' \\ 'Department of Pediatric Surgery,Virgen del Rocío Children's \\ Hospital, Spain \\ ${ }^{2}$ Escuela de Medicina, Universidad de las Américas, UDLA - \\ QUITO, Ecuador \\ ${ }^{3}$ Department of Plastic Surgery,Virgen del Rocío Children's \\ Hospital, Spain
}

\begin{abstract}
Correspondence: Grecia Victoria Vivas Colmenares, Escuela de Medicina, Universidad de las Américas, UDLA -QUITO, Ecuador, Nayon highway - Quito- Ecuador, Tel 0059399809 5130,Email Greciavc_10@hotmail.com
\end{abstract}

Received: December 132017 | Published: May 30, 2018
Abbreviations: PC, pentalogy of cantrell; ICU, intensive care unit; PTFE, polytetrafluoroethylene

\section{Introduction}

Pentalogy of Cantrell (PC) is a congenital and rare thoracoabdominal wall closure defect, described by J.R. Cantrell, Haller JA, MM Ravitch. ${ }^{1}$ Actually, prenatal diagnosis of PC can be made in the first trimester using transvaginal color doppler sonography. ${ }^{2}$

This syndrome is characterized by defects that involve supraumbilical abdominal wall (74.5\% of patients have omphalocele), lower region of the sternum $(59.4 \%)$, ventral diaphragm $(56.8 \%)$, diaphragmatic pericardium (41.8\%) and different cardiac defects. ${ }^{3}$ Survival is extremely rare and depends on the severity of cardiac defects and the degree of the associated anomalies. ${ }^{4,5}$ Associated intracardiac anomalies may include ventricular and atrial septal defects, Ebstein's anomaly, truncus arteriosus, transposition of great vessels, tetralogy of fallot, and hypoplastic left heart syndrome. ${ }^{6,7}$ We describe a late ventral hernia repair in a long survivor patient and a review of the published literature on this topic.

\section{Case report}

A full-term male newborn with a giant omphalocele and ectopia cordis was admitted in our hospital. Prenatal ultrasounds did not show abnormalities. His family history was unremarkable. Physical examination revealed an inferior sternal cleft with a giant omphalocele and thoraco-abdominal ectopia cordis. He underwent surgical repair two hours after birth. Surgical findings consisted with partial agenesis of lower sternum, left anterolateral diaphragmatic hernia, thoracoabdominal ectopia cordis, wide communication between thorax and abdomen, patent ductus arteriosus and large omphalocele that contained a part of the liver, small bowel loops and spleen.

A peritoneal flap was made to cover the heart placed in the right side of the thorax; the left lobe of the liver was placed covering the diaphragmatic defect and the abdominal wall was closed only by skin coverage. Any attempt to reduce the liver was associated with severe bradycardia that precluded complete closure. Due to the severe clinical situation of the patient and the large abdominal wall defect, closure with skin coverage was considered to be the best option for this unstable patient.

Postoperative time in the Intensive Care Unit (ICU) was satisfactory and he was discharged in good clinical condition 16 days after surgery. At four years old, he required a new surgical intervention for undescended testes; during this operation, the abdominal defect was reduced and the child suffered important changes in the cardiac function such as a severe bradycardia and hypotension. At this point, we did not make any other attempt to repair the abdominal defect.

Eighteen years later he was alive and had good psychomotor development, completely independent for daily activities. The patient had an abdominal defect with eventration of great part of the liver, $22 \times 24 \mathrm{~cm}$ approximately, with a midline scar secondary to the first surgery (Figure 1A) (Figure 1B) (Figure 2). Five years earlier surgery was offered, but it was refused. At eighteen years old, he finally decided to go ahead with a surgical repair. At surgery strong adhesions were released, we also performed appedectomy, cholecystectomy, epiplonectomy and removal of a serosal epidermal cyst. The wall defect presented large dimensions, being impossible to do the closure with the abdominal muscular or fascial transfer, as the muscles were severely hypotrophic and fibrotic. Muscular components separation transfer was considered but was not applicable to this case. The abdominal wall defect was repaired by using a double layer microporous polytetrafluoroethylene (PTFE) mesh, and skin closure was undertaken by overlapping a deepithelialized dermal flap from one side covered by the contralateral skin (Figure 1C) (Figure 1D) (Figure 3). 

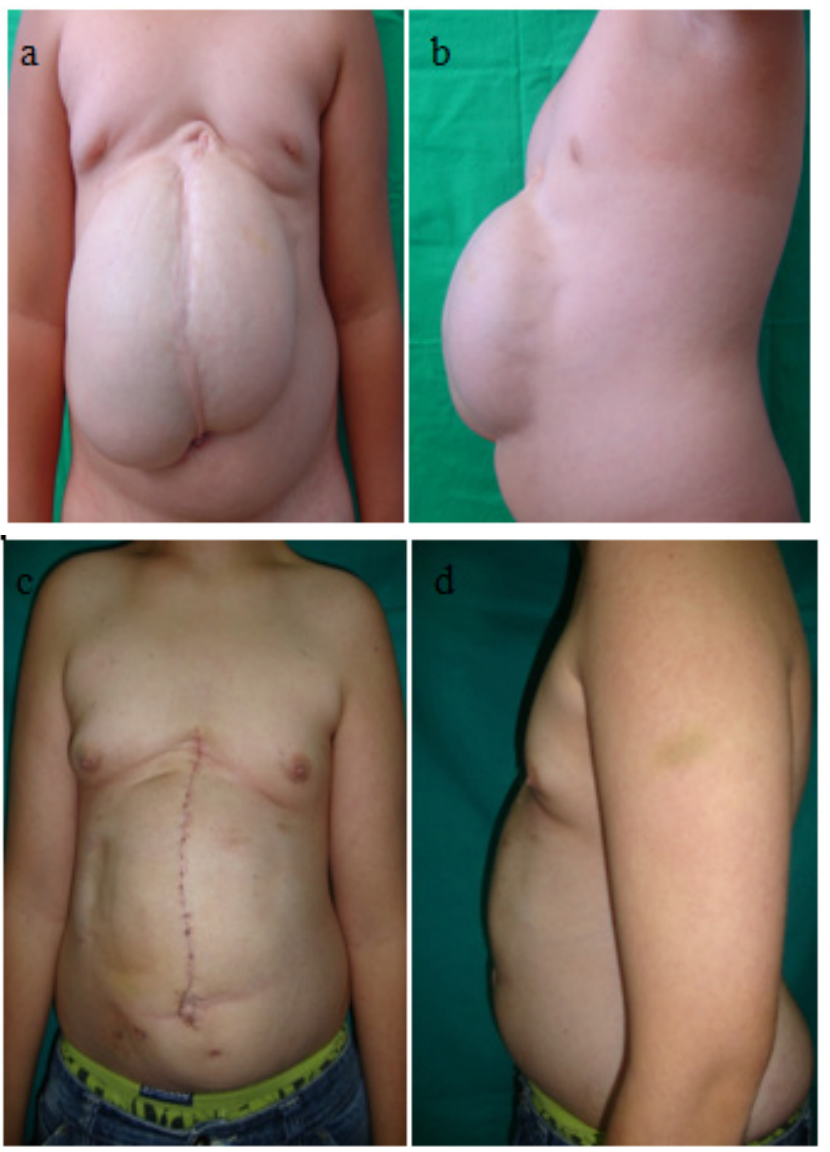

Figure I Anterior (A) and lateral (B) view of preoperative abdominal wall defect. Result of surgical correction of abdominal defect; anterior (C) and lateral $(D)$ views

A

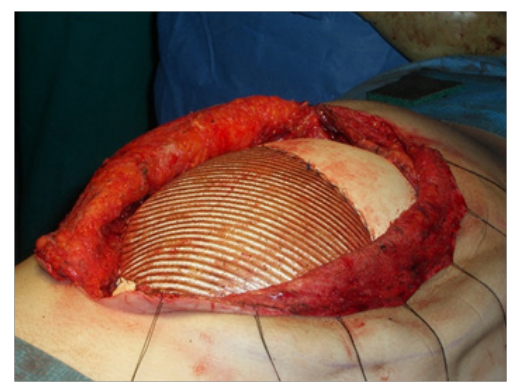

$B$

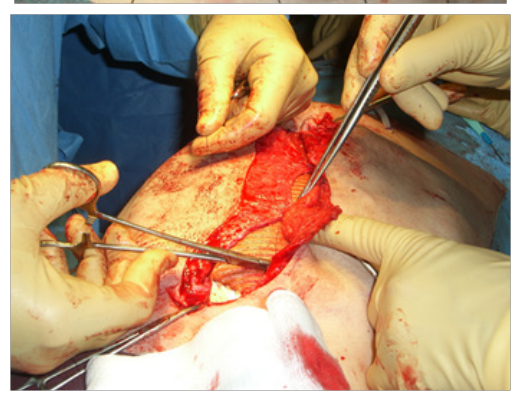

Figure 3 Intraoperative image: PTFE mesh (A) and dermal flaps (B)

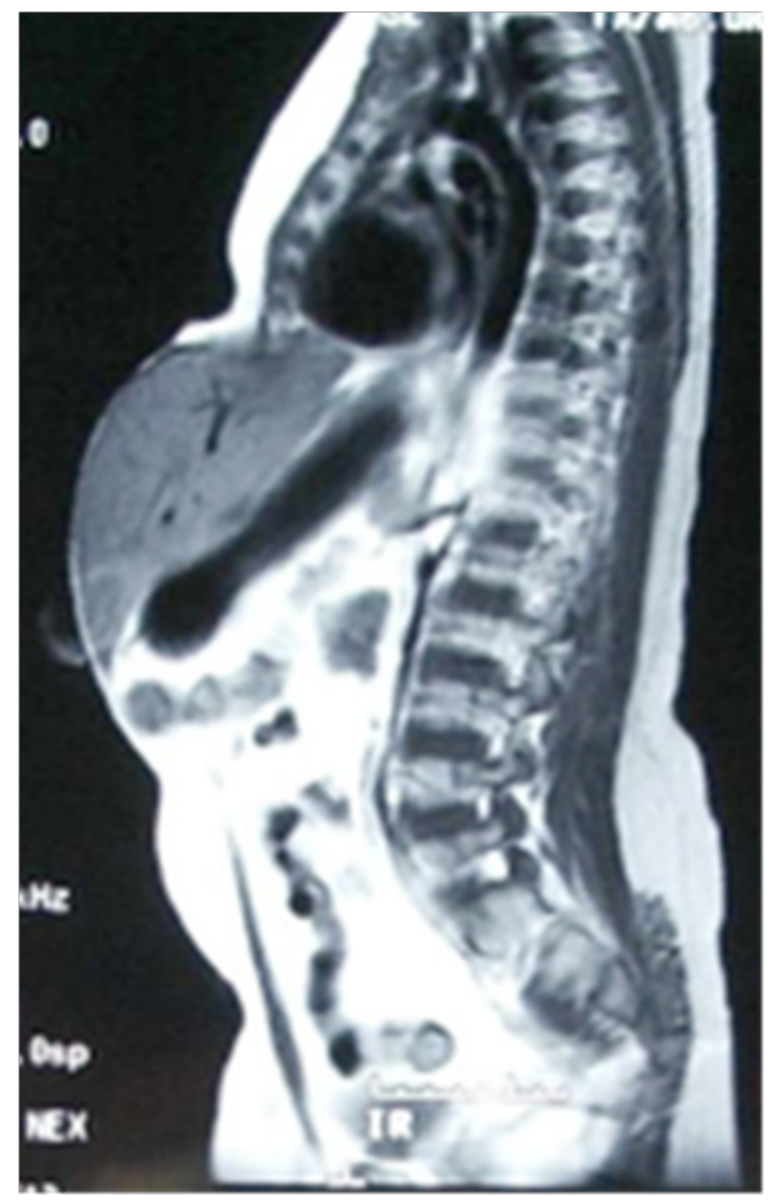

Figure 2 Abdominal MRI showing liver and stomach partially herniated through the abdominal wall defect

\section{Discussion}

PC is a rare entity and around 250 cases have been reported, with an estimated prevalence of $1 / 65.000$ to $1 / 200.000$ live births. ${ }^{8}$ Toyama et al. ${ }^{9}$ in 1972 suggested the following classification for the PC: Class 1, definite diagnosis, with all five defects present; Class 2, probable diagnosis, with four defects present, including intracardiac and ventral wall abnormalities; and Class 3, incomplete expression, with various combinations of defects present, including a sternal abnormality. Our case fits into Class 1 or complete PC. ${ }^{9}$

The etiology of PC is unknown. Most cases are sporadic and no recurrences have been reported. There is male dominance with a male to female ratio of $2.7: 1$. This syndrome has also been reported occasionally in association with sirenomelia, anencephaly and amniotic band syndrome. ${ }^{10}$

Several chromosome studies have showed inconsistent anomalies, some of them suggest an X-linked inheritance. ${ }^{11}$ Embryologic abnormalities seem to occur in the first 20 days of embryonic development (14-18 days). The main error presented in the mesoderm. The abnormal development of the epymiocardium originates cardiac defects and the wrong migration of mesodermal primordial structures, resulting in sternal and abdominal wall defects. In 1972, Barrow 
et al. ${ }^{12}$ induced ectopia cordis in rats by using aminopropionitrile between the 14th and 15th gestational days. ${ }^{12}$ In 1991, López de Torre et al. ${ }^{13}$ described experimental models of celosomies (omphalocele and pentalogy of Cantrell) in the chicken embryo by early aspiration of $5 \mathrm{ml}$ of egg albumin between the $14^{\text {th }}$ and $15^{\text {th }}$ gestational days. ${ }^{13}$

The survival of PC depends on the severity of the cardiac defects and the degree of the associated anomalies, being the existing of cardiac defects the most important factor of morbidity and mortality in this pathology. A multidisciplinary team should follow-up milder forms to determine the best time for termination of pregnancy. There are no studies assessing the best mode of delivery in cases of PC because this is a rare congenital anomaly with poor prognosis for which pregnancy termination is indicated in many countries. ${ }^{14}$ The repair of the omphalocele should not be delayed. Repair of the sternal, diaphragmatic, and pericardial defects can be attempted at the same time. ${ }^{15,16}$ Surgical correction is often difficult due to the hypoplasia of the thoraco-abdominal cavity and inability to close the wall defect as seen in our case. Norma et al. ${ }^{17}$ reported the outcome of 22 patients surgically treated of PC where the babies without ectopia cordis (EC) had a favorable outcome. ${ }^{17}$

In a review of 36 cases, Toyama et al., found a survival rate of $20 \%$ in patients affected of incomplete PC (mild variants and patients without intracardiac defects). ${ }^{9}$ In 1996, Hornberger et al. ${ }^{17}$ studied a group of 13 patients ( 2 infants with Pentalogy of Cantrell) with ectopia cordis and significant intracardiac defects; their conclusion was that in the absence of significant extracardiac defects, patients can survive beyond early infancy and undergo successful cardiac repair, while the patients with Pentalogy of Cantrell who presented important intracardiac defects (pulmonary venous confluence obstruction and right shunt placement) did not live more than 5 weeks. ${ }^{18}$

There are several techniques of ventral hernia repair, but not all are applicable to large hernias because a tension-free repair is a prerequisite to prevent recurrences. Direct repair of the abdominal wall defect is frequently impossible or is performed under tension, that prevents adequate closure and favors recurrences. ${ }^{19}$

In 1990 Ramirez and Dellon introduced the "components separation technique" (CST) to bridge the fascial gap without the use of prosthetic material. The technique is based on enlargement of the abdominal wall surface by separation and advancement of the muscular layers. In this way, defects of up to $20 \mathrm{~cm}$ at the waistline can be closed. ${ }^{20}$ In CST a tension-free repair is accomplished. In the literature recurrence rates of $0-28 \%$ have been reported for CST, although how was accomplished and follow-up are not well documented in most series. ${ }^{21}$ In our case there was an upper based defect, with the larger diameter at the costal border. This situation also precluded the successful use of CST.

Intraperitoneal prosthesis offers advantages, including a limited muscular layer dissection with subsequent less bleeding, and reduced postoperative intra-abdominal pressure. A review of literature shows that autologous tissues and biocompatible materials have been used for chest wall closure. Kim et al..$^{22}$ presented a neo-sternum reconstruction using costal cartilage approximation and small Permacol patch repair in the treatment of a newbornpatient with cantrell pentalogy, been succefully, but with a defect of only $3 \mathrm{~cm} .{ }^{22}$

Currently, the most commonly used prostheses are made of polypropylene, but they have some disadvantages, such as formation of intraperitoneal adhesions, obstructions and intestinal fistulas. ${ }^{23}$ Ventral hernia repair with mesh has resulted in a low recurrence rate, but the contact with the viscera produces a large inflammatory response with subsequent peritoneal complications. In order to minimize adhesions and maintain resistance, alternatives have been developed for polypropylene, with the introduction of polytetrafluoroethylene (PTFE), polypropylene/polyglactin, double side polypropylene/ carboxymethyl cellulose and polyester/polyethylene glycolglycerol collagen meshes. ${ }^{24}$ The expanded-PTFE dual patch has significantly better mechanical properties than polypropylene-mesh. The structure of the prostheses and the design of polytetrafluoroethylene monofilament fiber mesh are the goal to reduce the potential of bacterial colonization, as showed in an experimental study by Naufel et al. ${ }^{25,26}$ It is a soft pliable microporous material that prevents mechanical trauma to the viscera. The micropores on both sides of the patch are too small to allow ingrowth of fibrocollagenous tissue, thus preventing fibrous adhesions on the visceral side of the patch. ${ }^{26}$

\section{Conclusion}

In summary, a patient with class 1 of Pentalogy of Cantrell is presented. Initial surgery with partial correction of the defect allowed survival and good quality of life. For final correction we considered visceral partial reduction and abdominal wall closing with a microporous PTFE mesh and dermal flap as the best choice in this case. Long survival free of symptoms and excellent aesthetic results can be obtained by judicious combination of techniques.

\section{Acknowledgements}

None.

\section{Conflict of interest}

I. There are no prior publications or submissions with any overlapping information, including studies and patient.

II. No conflict of interest.

III. Each author listed on the manuscript has seen and approved the submission of this version of the manuscript and takes full responsibility for the manuscript.

\section{References}

1. Cantrell JR, Haller JA, Ravitch MM. A syndrome of congenital defects involving the abdominal wall, sternum, diaphragm, pericardium, and heart. Surg Gynecol Obstet. 1958;107(5):602-614.

2. Türkçapar AF, Sargın Oruc A, Öksüzoglu A, et al. Diagnosis of pentalogy of cantrell in the first trimester using transvaginal sonography and color Doppler. Case Rep Obstet Gynecol. 2015;2015:179298.

3. Vazquez-Jimenez JF, Muhler EG, Daebritz S, et al. Cantrell's syndrome: a challenger to the surgeon. Ann ThoracSurg. 1998;65:1178-85.

4. Harrison MR, Filly RA, Stanger P, et al. Prenatal diagnosis and management of omphalocele and ectopia cordis. J Pediatr Surg. 1982;17(1):64-66.

5. Spitz L, Bloom KR, Milner S, et al. Combined anterior abdominal wall, sternal, diaphragmatic, pericardial, and intracardiac defects: a report of five cases and their management. J Pediatr Surg. 1975;10(4):491-496.

6. Patil AR, Praveen LS, Ambica V. Pentalogy of cantrell: A case report. BJR Case Rep. 2015;201520140002. 
7. Swarray-Deen A, Seffah JD, Antwi-Agyei DA. Two cases of Pentalogy of Cantrell diagnosed antenatally at Korle Bu Teaching Hospital, Accra. Ghana Med J. 2017;51(4):191-195.

8. Desselle C, Herve P, Toutain A, et al. Pentalogy of Cantrell: sonographic assessment. J Clin Ultrasound. 2007;35(4):216-220.

9. Toyama WM. Combined congenital defects of the anterior abdominal wall, sternum, diaphragm, pericardium and heart: A case report and review of the syndrome. Pediatrics. 1972;50(5):778-791.

10. Bittmann S, Ulus H, Springer A. Combined pentalogy of Cantrell with Tetralogy of Fallot, gall bladder agenesis, and polyspleenia: A case report. J Pediatric Surg. 2004;39(1):107-109.

11. Carmi R, Barbash A, Mares AJ. The thoracoabdominal syndrome (TAS): a new X-linked dominant disorder. Am J Med Genet. 1990;36(1):109-114.

12. Barrow MV, Willis LS. Ectopiacordis and gastroschisis induced in rats by maternal administration of lathyrogen, beta-aminopropionitrile. Am Heart J. 1972;83(4):518-526.

13. Lopez de Torre B, Aldazabal P, Uriarte S, et al. The experimental production of abdominal wall defects in the chick embryo. Cir Pediatr. 1991;4(2):108-111.

14. Araujo Júnior E, Carrilho MC, Toneto BR, et al. Pentalogy of Cantrell: Prenatal Diagnosis, Delivery, and Immediate Postnatal Surgical Repair. $J$ Neonatal Surg. 2017;6(2):32.

15. Fernandez MS, Lopez A, Vila JJ, et al. Cantrell's pentalogy: Report of four cases and their management. Pediatr Surg Int. 1997;12(5-6):428-431.

16. Norma BS, Alfredo VA, Erika SS, et al. Pentalogy of Cantrell. Forty- two years of Experience in the Hospital Infantil de Mexico Federico Gomez. World J Pediatr Congenital Heart Surg. 2011;2(2):211-218.

17. Hornberger LK, Colan SD, Lock JE, et al. Outcome of patients with ectopia cordis and significant intracardiac defects. Circulation. 1996:94(9 Suppl):1132-1137.
18. Briennon X, Lermite E, Meunier K, et al. Surgical treatment of large incisional hernias by intraperitoneal insertion of Parietex $(\mathrm{R})$ composite mesh with an associated aponeurotic graft (280 cases). J Visc Surg. 2011;148(1):54-58

19. Ramirez OM, Ruas E, Dellon AL. "Components separation" method for closure of abdominal-wall defects: an anatomic and clinical study. Plast Reconstr Surg. 1990;86(3):519-526.

20. De Vries Reilingh TS, van Goor H, Rosman C, et al. "Components separation technique" for the repair of large abdominal wall hernias. $J \mathrm{Am}$ CollSurg. 2003;196(1):32-37.

21. Greenawalt KE, Butler TJ, Rowe EA, et al. Evaluation of sepramesh biosurgical composite in a rabbit hernia repair model. J Surg Res. 2000;94(2):92-98.

22. Kim CW, Cho HM, Son BS, et al. Neo-sternum reconstruction using costal cartilage approximation and small Permacol patch repair in the treatment of Cantrell pentalogy: a case report. J Cardiothorac Surg. 2015;10:40.

23. Burger JW, Halm JA, Wijsmuller AR, et al. Evaluation of new prosthetic meshes for ventral hernia repair. Surg Endosc. 2006;20(8):1320-1325.

24. Naufel AM, Czeczko NG, Mafafaia O, et al. Comparative study between meshes of polyester with collagen and polytetrafluoroethylene in the repair of defects produced in abdominal wall of rats. Acta Cir Bras. 2012;27(7):454-459.

25. Melman L, Jenkins ED, Hamilton NA, et al. Histologic and biomechanical evaluation of a novel macroporous polytetrafluoroethylene knit mesh compared to lightweight and heavyweight polypropylene mesh in a porcine model of ventral incisional hernia repair. Hernia. 2011;15(4):423-431.

26. De Vries Reilingh TS, van Goor H, Charbon JA, et al. Repair of Giant Midline Abdominal Wall Hernias: "Components Separation Technique" versus Prosthetic Repair. World J Surg. 2007;31(4):756-763. 